\title{
Reorganization energy for hole and electron transfer of poly(3-hexylthiophene) derivatives
}

\author{
Eliezer Fernando Oliveira ${ }^{\text {a }}$, Francisco Carlos Lavarda a, b, * \\ ${ }^{a}$ UNESP - Univ Estadual Paulista, POSMAT - Programa de Pós-Graduação em Ciência e Tecnologia de Materiais, Bauru, SP, Brazil \\ ${ }^{\mathrm{b}}$ DF-FC, UNESP - Univ Estadual Paulista, Av. Eng. Luiz Edmundo Carrijo Coube 14-01, 17033-360 Bauru, SP, Brazil
}

\section{A R T I C L E I N F O}

\section{Article history:}

Received 2 March 2016

Received in revised form

19 June 2016

Accepted 1 July 2016

Available online 1 July 2016

\section{Keywords:}

P3HT

P3HT derivatives

Hole transport

Electron transport

Density functional theory

\begin{abstract}
A B S T R A C T
Poly(3-hexylthiophene) (P3HT) is a common material used as electron donor element in active layers of organic solar cells. Previous studies have shown that is possible to improve the electronic properties of the P3HT through chemical substitutions in the empty beta-position of the thiophene rings; however, up to now it was not reported the effect of chemical substitutions in the charge transport properties of the P3HT. In this work we theoretically investigate the reorganization energy related to the transport of holes and electrons of P3HT and 19 derivatives, employing a combination of density functional theory to calculate the electronic structure and a semiempirical method to optimize the geometry. Our results show that the chemical substitutions are able to improve the charge carrier transfer rate, but certain substituents tend to favour a greater transport of electrons than holes, which is not desirable for polymeric electron donor materials.
\end{abstract}

๑ 2016 Elsevier Ltd. All rights reserved.

\section{Introduction}

The search for less expensive and more efficient renewable energy sources has led the scientific community to pursue the improvement of organic solar cells, which currently has reached an efficiency of approximately $11 \%$ in converting solar into electrical energy [1]. This degree of efficiency obtained in laboratory for cells typically around $1 \mathrm{~cm}^{2}$ could be enough for the commercialization of this technology $[1,2]$, but organic solar cells still have other practical deficiencies to be overcomed in order to be marketed, such as degradation in the environment, solubility of its components, bandgap energy of the electron donor element, morphology control and large-scale production, among others [3-7].

The most common type of active layer of organic solar cells is made from blends of conjugated materials with $\mathrm{C}_{60}$ derivatives and exhibit the highest levels of efficiency [8-10]. One of the conjugated materials employed in these blends as electron donor is the regioregular poly(3-hexylthiophene) (P3HT), a polythiophene derivative that, blended with phenyl- $\mathrm{C}_{61}$-butyric acid methyl ester (PCBM), has yielded organic solar cells with good efficiencies compared to the other combinations of electron and donor

\footnotetext{
* Corresponding author.

E-mail address: lavarda@fc.unesp.br (F.C. Lavarda).
}

materials [11-14]. We have shown before that employing chemical modifications in the empty beta-position of monomeric units of regioregular P3HT one can design new derivatives with significant variations in bandgap, solubility or in the energy of electronic frontier orbitals $[15,16]$; in this way, considering a combination with PCBM, it was possible to find new P3HT derivatives that could increase the power conversion efficiency (PCE) of the solar cell [16]. However, in that study it was not verified the impact of the chemical substitutions in the charge transport of the P3HT derivatives, property that has a considerable influence in the solar cell efficiency [17,18].

In this work we are interested in the influence of chemical substitutions on the reorganization energy $(\lambda)$ of regioregular P3HT, one of the properties related to the charge transport. The reorganization energy is the energy required for the geometric relaxation in the charge transfer, and it is inversely proportional to the mobility of charge carriers [19-22]. A greater mobility of holes than electrons is important for electron donor materials that are employed in active layers of organic solar cells $[23,24]$. It is found in the literature that the regioregular P3HT can achieve a hole mobility of around $10^{-4}-10^{-3} \mathrm{~cm}^{2} / \mathrm{V}[25,26]$, which is considered moderate [26]. However, the greater this mobility, the better the device performance will be $[17,18,22,25,26]$.

As it is desired to increase hole mobility of electron donor polymers, it is interesting to study the reorganization energies 
related to the transport of holes $\left(\lambda_{\text {hole }}\right)$ and electrons $\left(\lambda_{\text {electron }}\right)$ in order to determine whether some kind of substituent may provide a greater mobility of electrons instead of holes.

Using Density Functional Theory (DFT), we calculated the energies $\lambda_{\text {hole }}$ and $\lambda_{\text {electron }}$ for P3HT and 19 derivatives. The results showed that the charge mobility always improves with the insertion of substituents on P3HT, but there are cases in which the electron mobility is shown to be larger than the hole mobility.

\section{Materials and methods}

We studied P3HT and 19 of its derivatives (see Fig. 1), in which we replace the hydrogen in the empty beta-position of each monomeric unit by $\mathrm{Cl}$ (P3HT-Cl), Br (P3HT-Br), F (P3HT-F), $\mathrm{SCH}_{3}$ (P3HT-SCH $), \mathrm{OH}$ (P3HT-OH), NH $\mathrm{NH}_{2}\left(\mathrm{P} 3 \mathrm{HT}-\mathrm{NH}_{2}\right), \mathrm{CH}_{3}\left(\mathrm{P} 3 \mathrm{HT}-\mathrm{CH}_{3}\right)$, $\mathrm{C}_{2} \mathrm{H}_{5}\left(\mathrm{P} 3 \mathrm{HT}-\mathrm{C}_{2} \mathrm{H}_{5}\right), \mathrm{C}_{3} \mathrm{H}_{7}\left(\mathrm{P} 3 \mathrm{HT}-\mathrm{C}_{3} \mathrm{H}_{7}\right), \mathrm{C}_{4} \mathrm{H}_{9}\left(\mathrm{P} 3 \mathrm{HT}-\mathrm{C}_{4} \mathrm{H}_{9}\right)$, cyano (P3HT-CN), a six-carbon piece of trans-polyacetylene (P3HT-TPA), phenyl (P3HT-Ph), phenylene vinylene (P3HT-PV), $\mathrm{CF}_{3}\left(\mathrm{P} 3 \mathrm{HT}-\mathrm{CF}_{3}\right)$, $\mathrm{N}\left(\mathrm{CH}_{3}\right)_{2}\left(\mathrm{P} 3 \mathrm{HT}-\mathrm{N}\left(\mathrm{CH}_{3}\right)_{2}\right), \mathrm{OCH}_{3}\left(\mathrm{P} 3 \mathrm{HT}-\mathrm{OCH}_{3}\right), \mathrm{COOH}(\mathrm{P} 3 \mathrm{HT}-\mathrm{COOH})$ and $\mathrm{CH}=\mathrm{CH}_{2}\left(\mathrm{P} 3 \mathrm{HT}-\mathrm{CH}=\mathrm{CH}_{2}\right)$. We chose to use oligomers with 10 repeat units (decamer) for each case studied with the purpose of observing trends occurring in the reorganization energy due to chemical substitutions. Employing decamers for this study is reasonable, since a previous work suggests use of oligomers with a minimum of six monomeric units to better describe the polaron effects [27]. Some of these substitutions were chosen because they were already synthesized [28-33]. It will be interesting to observe the results for the fluorinated derivative, since it is known that the fluorine atom generally improves hole mobility of polymers or small molecules [28,30,34-36].

The charge transport in conducting polymers happens primarily via the hopping mechanism [19-22,37]. Studies suggest that the mobility $(\mu)$ of the charge carriers (electrons or holes) via hopping is directly proportional to the transfer rate $\left(\mathrm{K}_{\mathrm{CT}}\right)$ of charge carriers (hopping probability per unit time) described by the Einstein relationship (Eq. (1)) [38-40]:

$\mu=\frac{e A^{2}}{k_{B} T} K_{C T}$

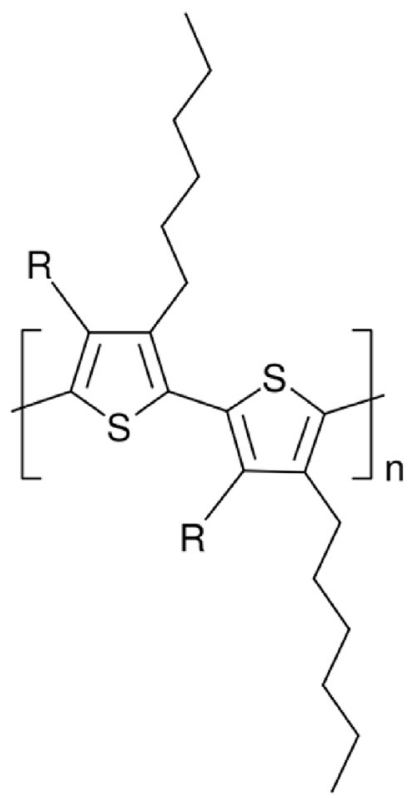

Fig. 1. Structural formula of P3HT and its derivatives studied in this work. in which $\mathrm{k}_{\mathrm{B}}, \mathrm{T}, e$, and A are, respectively, the Boltzmann constant, temperature, elementary charge, and the hopping transport distance. According to the Marcus-Hush semiclassical model for the inter-chain charge transfer in organic materials [19-22,38-40], the key parameters that govern the behaviour of the charge transfer rate are the reorganization energy due to geometric relaxation in the charge transfer $(\lambda)$ and the orbital overlap of neighbouring interacting chains (electronic coupling) [22,38]. Thus, the charge transfer rate may be expressed as follows (Eq. (2)) [19,41]:

$K_{C T}=\left(\frac{\pi}{\lambda k_{B} T}\right)^{\frac{1}{2}}\left(\frac{2 \pi\left\langle H_{a b}\right\rangle^{2}}{h}\right) e^{\left(\frac{-\lambda}{4 k_{B} T}\right)}$

in which $h$ and $\left\langle\mathrm{H}_{\mathrm{ab}}\right\rangle$ are the Planck constant and the electronic coupling matrix element between neighbouring interacting chains, respectively. Hutchison et al. [19] studied the charge transfer rate for a group of 21 conjugated polymers and they have shown that, for charge transfer rates according to Marcus-Hush theory (Equation (2)), while the contribution of $\left\langle\mathrm{H}_{\mathrm{ab}}\right\rangle\left(2 \pi\left\langle\mathrm{H}_{\mathrm{ab}}\right\rangle^{2} / \mathrm{h}\right)$ starts to saturate for oligomers with more than 5 monomeric units, the exponential contribution $\left(\mathrm{e}^{(-\lambda / 4 \mathrm{kBT})}\right)$ keep increasing and for more than 7 monomeric units it dominates the behaviour of the charge transfer rate; in this exponential part, we find the reorganization energy $\lambda$ (the exponential part will increase because $\lambda$ decreases with increasing oligomer length, as will be discussed bellow). It is also expected that the transfer coupling saturates in some point, once it depends on the conjugation length of the polymers [38]. So, for long oligomers and in the polymer limit, the exponential nature of the reorganization energy contribution dominates and in this way, it is the most important parameter to be studied to estimate the charge carrier transport $[19,22,38]$. The reorganization energy is the sum of two contributions [42,43]: the internal $\left(\lambda_{\text {int }}\right)$ and external $\left(\lambda_{\text {ext }}\right)$ reorganization energies. In the charge transfer process, $\lambda_{\text {int }}$ arises from the geometric changes in the molecule and $\lambda_{\text {ext }}$ is related to the environmental variations that occur by polarization of the surrounding medium [42,43]. As it is estimated that $\lambda_{\text {ext }} \ll \lambda_{\text {int }}\left(\lambda_{\text {ext }} \sim 0.01 \mathrm{eV}\right)$, the external contribution is often neglected $[19,32]$. Thus, in this work we will consider that $\lambda=\lambda_{\text {int }}$.

As the hole transfer rate is inversely proportional to the reorganization energy in the process, the larger this energy, the worse the hole mobility of the material $[19,20]$. Thus, the search for new materials with low reorganization energy is a good starting point for studies of charge transport properties of donor polymers for active layers of organic solar cells.

When a greater mobility of holes is required, it is important to study the hole transfer rate $\left(\mathrm{k}_{\text {hole }}\right)$. In this case, the reorganization energy is evaluated based on the potential energy surfaces for the transition of the neutral compound to a positively charged compound, as shown in Fig. 2 [19-21].

The parameters involved in Fig. 2 are:

- $\mathrm{M}$ and $\mathrm{M}^{+}$represent the neutral species and that containing the hole;

- $\Delta \mathrm{q}$ is the change in geometry;

- $\mathrm{E}^{(0)}(\mathrm{M})$ and $\mathrm{E}^{(0)}\left(\mathrm{M}^{+}\right)$represent the energy of neutral and cationic states in the lower energy geometry;

- $\mathrm{E}^{(1)}\left(\mathrm{M}^{+}\right)$and $\mathrm{E}^{(1)}(\mathrm{M})$ represent the energy of cationic state in the geometry of the neutral molecule and the energy of neutral molecule in the geometry of the cationic molecule, respectively;

- $\Delta \mathrm{E}$ is the energy of adiabatic ionization;

- $\lambda_{h}^{(1)}$ and $\lambda_{h}^{(2)}$ are the energies of the geometric relaxation of neutral and cationic states, respectively.

Thus, the reorganization energy for hole transfer ( $\left.\lambda_{\text {hole }}\right)$ is 


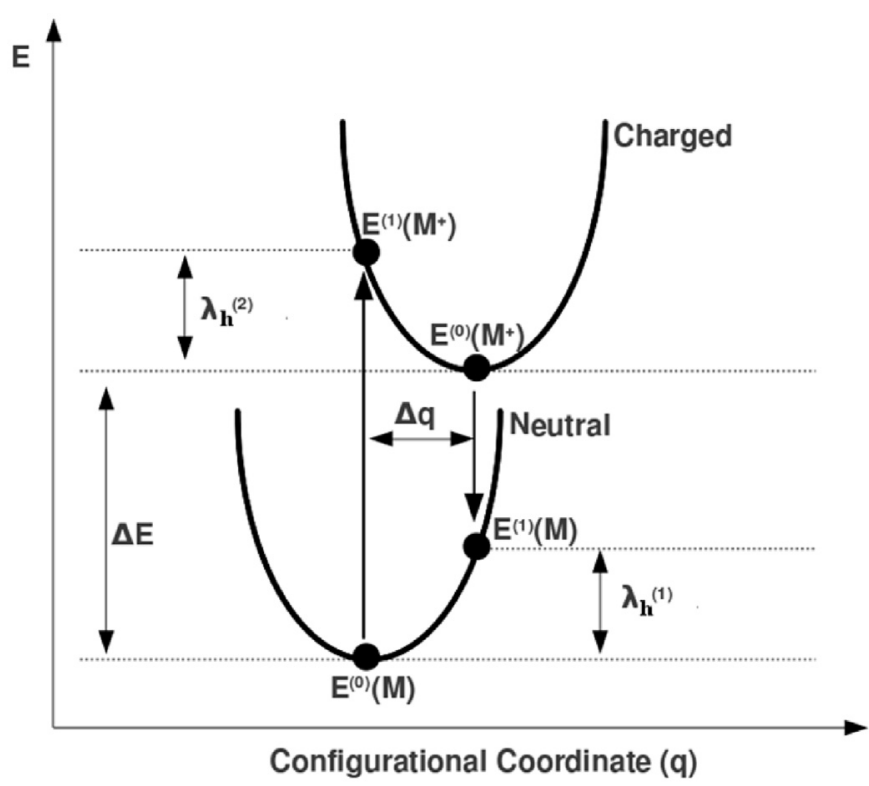

Fig. 2. Potential energy surfaces for the neutral and positively charged structures (See text for definitions of displayed quantities).

defined as [19-21]:

$\lambda_{\text {hole }}=\lambda_{h}^{(1)}+\lambda_{h}^{(2)}$

in which $\lambda_{h}^{(1)}=\mathrm{E}^{(1)}(\mathrm{M})-\mathrm{E}^{(0)}(\mathrm{M})$ and $\lambda_{\mathrm{h}}^{(2)}=\mathrm{E}^{(1)}\left(\mathrm{M}^{+}\right)-\mathrm{E}^{(0)}\left(\mathrm{M}^{+}\right)$. In an analogous way, we can evaluate the reorganization energy for electron transfer $\left(\lambda_{\text {electron }}\right)$ by Eq. (4):

$\lambda_{\text {electron }}=\lambda_{e}^{(1)}+\lambda_{e}^{(2)}$

in which $\lambda_{\mathrm{e}}^{(1)}=\mathrm{E}^{(1)}(\mathrm{M})-\mathrm{E}^{(0)}(\mathrm{M})$ and $\lambda_{\mathrm{e}}^{(2)}=\mathrm{E}^{(1)}\left(\mathrm{M}^{-}\right)-\mathrm{E}^{(0)}\left(\mathrm{M}^{-}\right)$.

Considering the size of the systems, as well as the amount of conformers analysed, the exclusive use of $a b$-initio methods would result in a high computational cost. Thus, we chose to use a geometric structure optimized by a semiempirical method and to obtain the electronic structure data from DFT [44]. Such an approach has been applied with satisfactory results in studies with conjugated polymers [15,16,45-47].

As the idea is to study only decamers of each structure, considered a long oligomeric chain, it is important to study the behaviour of the small oligomers before to determine the structure of the most stable long oligomer. In order to obtain the most stable decamers, we used a methodology we have recently proposed [48]. We adopted structures with Head-to-Tail-Head-to-Tail regioregularity, since this configuration promotes a decreased steric interactions among the side chains of the polymer, favouring a long conjugation length and better crystallinity which gives the best configuration for polymeric materials for use in organic solar cells $[1,49,50]$. We used molecular dynamics simulation with the AMBER force field [51], implemented in Gabedit [52], in order to obtain a large number of uncorrelated structures for monomers, dimers and tetramers; this initial step helped us to search the most probable initial geometry to build the decamer of P3HT, considering the conformation of the alkyl ramifications, dihedral angles between thiophenic rings and the interaction between neighbouring ramifications. After obtaining the decamer of P3HT, we made the chemical substitutions proposed in this paper and re-optimized the new structures. All structures, neutral and charged, were completely optimized by the semiempirical method PM6 [53] implemented in the MOPAC2012 computational package [54]. We chose the PM6 Hamiltonian due to its satisfactory performance in studies of conjugated polymers and derivatives of P3HT $[12,15,16,46,47,55,56]$.

After the optimization of all geometries, we calculated the electronic structure data of decamers using DFT, employing the hybrid functional B3LYP [57] with GAMESS software [58]. This functional was chosen for its good results regarding polymeric materials [59]. For charged structures, a restricted open-shell Kohn-Sham (ROKS) approach was employed to prevent spin contaminations [57]. The basis function set chosen was the $6-31 \mathrm{G}(\mathrm{d})$ [60]. DFT/B3LYP/6-31G(d) methodology has been widely used in studies of conjugated polymers $[59,61]$ and has been found adequate to predict the electronic properties $[15,16,27,46,47,59,62]$.

In all calculations performed we employed a dielectric constant equal to 3.0, which is an average value for conjugated organic polymers [63], in order to simulate the presence of neighbouring chains in the solid state via the conductor-like screening model (COSMO) [64].

\section{Results and discussion}

We present in Fig. 3 the results for the reorganization energy related to the transfer of holes and electrons for decamers that were studied using Eqs. (3) and (4); these results are reproduced in Table S1 of the Electronic Supplementary Material. Experimental studies estimate $\lambda_{\text {hole }}$ to be approximately $0.1 \mathrm{eV}$ for a chain length of 20 monomers of P3HT [43], compared to our theoretical value of $0.93 \mathrm{eV}$. We must point out that our study was conducted using decamers. As shown before by us and some experimental studies $[12,48,65,66]$, a saturation in the optical and electronic properties of polythiophene derivatives do not change anymore for 21-24 monomeric units or more, even that slightly modifications are also observed up to 96 monomeric units [67]; it is also known that the reorganization energy tends to decrease with the increasing size of polymer chains $[19,43,68,69]$. So, being aware of these facts, the value obtained in this work for $\lambda_{\text {hole }}$ of P3HT is reasonable. We did not find experimental estimates for $\lambda_{\text {electron}}$.

As discussed above, the charge transfer rate is inversely proportional to reorganization energy. So, we are looking for (i) P3HT derivatives with lower values of $\lambda_{\text {hole }}$ when compared with pure P3HT, and (ii) for electron donor polymers that have a $\lambda_{\text {hole energy }}$

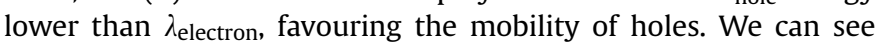
from Fig. 3 that the theoretical results for $\lambda_{\text {hole }}$ and $\lambda_{\text {electron }}$ indicate that chemical modifications can be an interesting tool for increasing mobility of holes and electrons, because all derivatives showed lower values than P3HT. However, care must be taken with the choice of substituent, since it is noted that some of the results obtained for $\lambda_{\text {electron }}$ showed a lower value than $\lambda_{\text {hole }}$, favouring a greater transfer rate for electrons than for holes. This can be observed in the substitutions with $\mathrm{OH}, \mathrm{NH}_{2}, \mathrm{TPA}, \mathrm{PV}, \mathrm{N}\left(\mathrm{CH}_{3}\right)_{2}$ and $\mathrm{OCH}_{3}$. The results obtained for P3HT showed $\lambda_{\text {hole }}<\lambda_{\text {electron, sug- }}$ gesting that hole mobility is higher than electron mobility; this result is consistent with what has been found experimentally $[25,26]$. As also noted in other materials [34-36], P3HT-F showed $\lambda_{\text {hole }}$ to be lower than that of P3HT, confirming that the fluorination process improves the conductivity of holes. Finally, it seems that the largest substituents lead to lower values for $\lambda_{\text {hole }}$ and $\lambda_{\text {electron}}$; the lowest result obtained for $\lambda_{\text {hole }}$ was for P3HT-TPA, with a value of $0.264 \mathrm{eV}$, whereas the lowest value of $\lambda_{\text {electron }}$ was $0.236 \mathrm{eV}$ for P3HT-PV (approximately 71\% and 77\% lower than that of the P3HT, respectively). Thus, we decided to analyse the dependency of $\lambda_{\text {electron }}$ and $\lambda_{\text {hole }}$ on the size of the substituent as represented by its volume. It is interesting to analyse this property because some large substituents can cause steric hindrance in the polymer chain when 


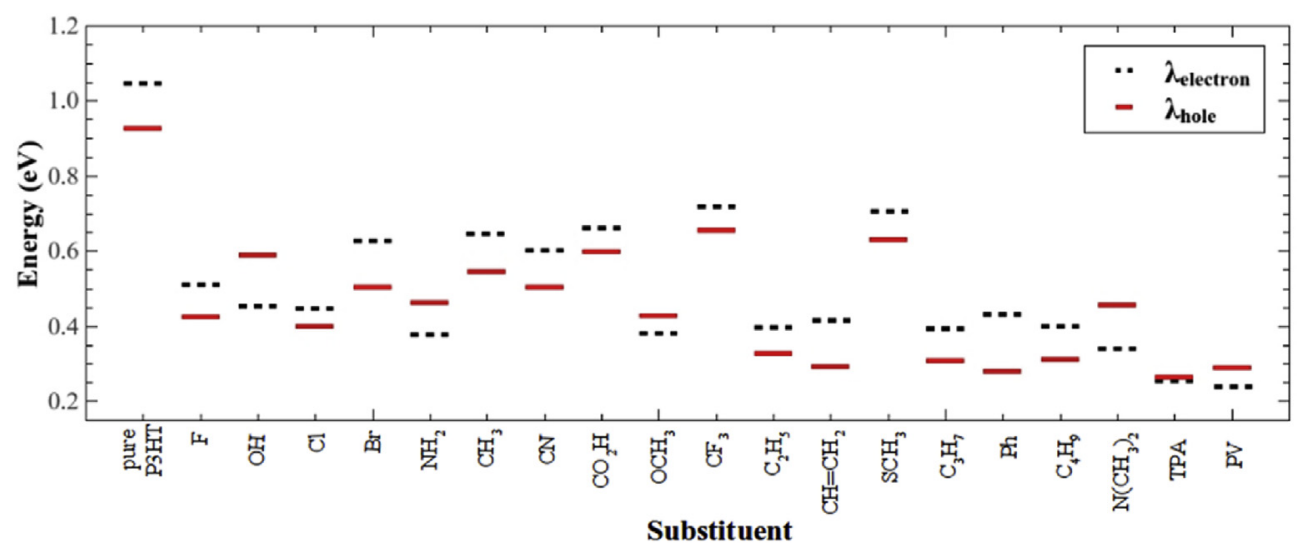

Fig. 3. Results for $\lambda_{\text {hole }}$ and $\lambda_{\text {electron }}$ for P3HT and its derivatives.

they receive (or lose) charge, resulting in a more rigid polymer chain [70]; thus, the substituent's ability to introduce rigidity in the polymer chain will result in a smaller conformational difference between the neutral and charged states, resulting in a lower reorganization energy.

Although there is very strong evidence that the P3HT and its derivatives have chains with the anti conformation [15,48,71-73], we also performed some calculations of the reorganization energy considering both conformations, anti and syn. Table S2 of Electronic Supplementary Material presents the reorganization energies for holes and electrons for P3HT and P3HT-F pentamers. As expected, since the conformation is very important in order to determine the reorganization energy, the energies for different conformations are not the same. However, the trend is that the syn conformation shows always the higher energy, keeping $\lambda_{\text {hole }}<\lambda_{\text {electron}}$. In other words, even considering the syn conformation, the reorganization energy of P3HT derivatives is lower than pure P3HT, which means that the conclusions based in the anti or syn configurations are the same.

Fig. 4 shows the relationship between $\lambda_{\text {hole }}$ and $\lambda_{\text {electron }}$ and the volume of the substituents. We can see that, although we have a distribution of points somewhat scattered, the expected result is observed: the greater the volume of substituent, the lower the $\lambda_{\text {hole }}$ and $\lambda_{\text {electron. }}$ However, there is no correlation between the volume

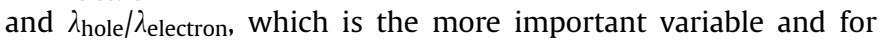
donor polymers should be lower than unity. Therefore, despite some large substituents having low $\lambda_{\text {hole }}$ values, considering the behaviour of both $\lambda_{\text {hole }}$ and $\lambda_{\text {electron, }}$ this is an inconclusive result. As we shall see later, the substituent's volume still plays an important role in obtaining small values of $\lambda_{\text {hole }} / \lambda_{\text {electron }}$ when considering also the charge exchange between the substituent and the polymer main chain. For instance, the results for alkyl groups show that the increase in size provides an improvement in $\lambda_{\text {hole, always keeping }}$

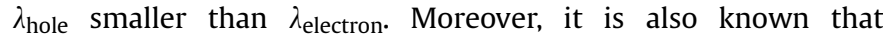
increasing the size of the alkyl groups implies a smaller charge transfer to the main chain [46].

Park et al. [74] performed a study in which chemical substitutions were made in anthracene, using the substituents $\mathrm{OH}$, $\mathrm{OCH}_{3}, \mathrm{CH}_{3}, \mathrm{~F}, \mathrm{Cl}, \mathrm{Br}$ and $\mathrm{CN}$. The authors found that the substituents caused changes in reorganization energy and their conclusion was similar to our own: in general, substitutions tend to improve the mobility of holes, except for $\mathrm{OH}$ and $\mathrm{OCH}_{3}$, which showed a lower $\lambda_{\text {electron }}$ than $\lambda_{\text {hole, }}$ thus favouring electron mobility, in agreement with our findings. Comparing their results with the known Hammet constants for the substituents [75] apparently the fewer electrons the substituent adds to the main chain, the lower the reorganization energy related to the hole transfer rate; no correlation was observed for the electron transfer rate. Thus, we decided to study how $\lambda_{\text {hole }}$ and $\lambda_{\text {electron }}$ vary based on the donor and acceptor properties of the employed substituents.

The Hammett constants are pure numbers and indicate how a substituent will interfere in the electron density of the material that
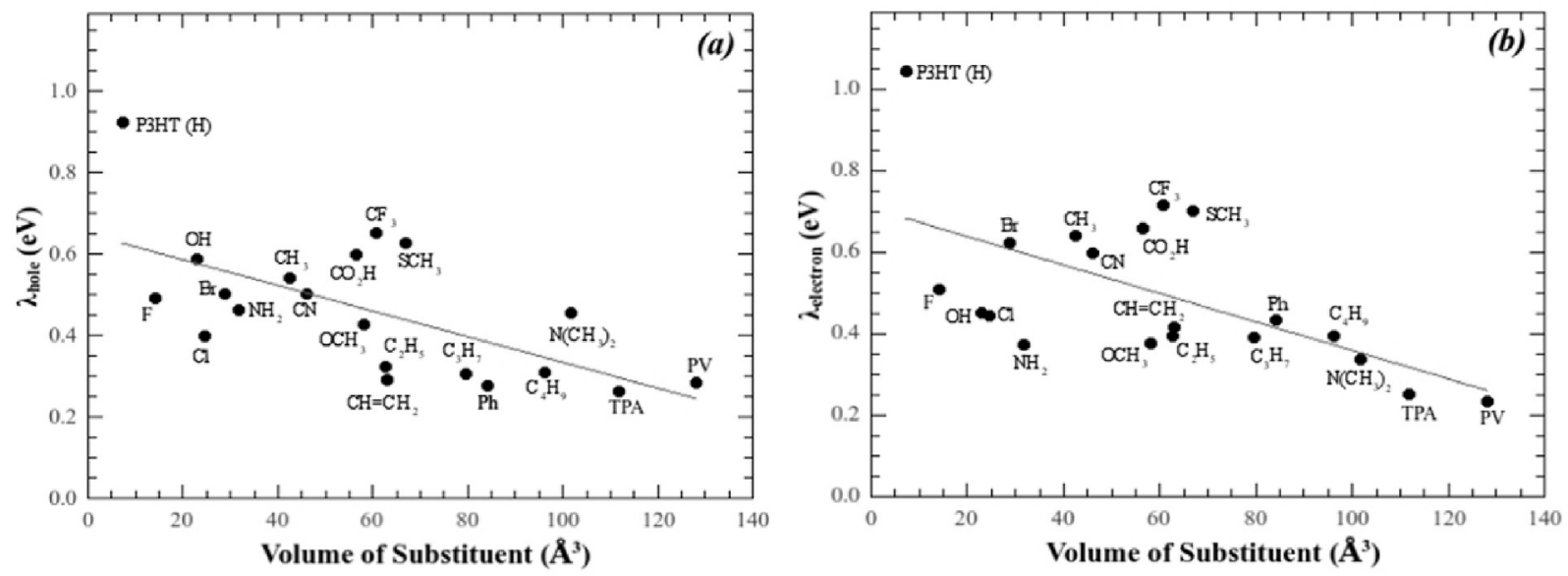

Fig. 4. Relationship between (a) $\lambda_{\text {hole }}$ and (b) $\lambda_{\text {electron }}$ and the volume of substituents. 
hosts the chemical substitution; a negative constant indicates that the substituent will release charge, and a positive value means that the substituent will withdraw charge from the main chain [75]. The charge exchange by inductive effect occurs through $\sigma$ bonds, while in the resonance effect it takes place through $\pi$ bonds [76]. Our study to verify a correlation with the reorganization energy will contain only the substituents for which there are Hammet constants available or for which we could provide a safe estimate. These are shown in Table 1, where we present the constants for inductive $\left(\sigma_{I}\right)$ and resonance $\left(\sigma_{R}\right)$ effects [75]. We note that the substituents have a good range of Hammet constants, which is important when performing a comprehensive analysis of influence on $\lambda_{\text {hole }}$ and $\lambda_{\text {electron }}$ of P3HT derivatives. The Hammet constant for resonance effect for the $\mathrm{SCH}_{3}$ group is not present in Table 1 because it does not induce such an effect [76]. The overall effect of charge exchange can be expressed by $\sigma$, which is defined by the sum $\sigma_{I}+\sigma_{R}$. We made estimates for $\sigma$ for the alkyl groups $\mathrm{C}_{3} \mathrm{H}_{7}$ and $\mathrm{C}_{4} \mathrm{H}_{9}$, since we have the values for $\mathrm{CH}_{3}$ and $\mathrm{C}_{2} \mathrm{H}_{5}(-0.17$ and -0.15 , respectively). It is known that the effect of alkyl side chains length on the electronic properties of thiophene-based conjugated polymers is felt up to three carbon atoms. So, we estimate the $\sigma$ constant for $\mathrm{C}_{3} \mathrm{H}_{7}$ and $\mathrm{C}_{4} \mathrm{H}_{9}$ as being -0.13 .

The plots of $\lambda_{\text {hole }}$ and $\lambda_{\text {electron against }} \sigma_{\mathrm{I}}$ and $\sigma_{\mathrm{R}}$ showed several trends that are best summarized in the plot of $\lambda_{\text {hole }} / \lambda_{\text {electron }}$ versus $\sigma$ (Fig. 5). As all the substituted chains showed a $\lambda_{\text {hole }}$ better (lower) than P3HT, what interests us are polymers with $\lambda_{\text {hole }} / \lambda_{\text {electron }}<1$, which implies a better hole mobility than electron mobility; the desired result is the lowest possible ratio. In Fig. 5, the sector for $\lambda_{\text {hole }} / \lambda_{\text {electron }}>1$ shows the substituents for which electron mobility is favored - which is not interesting for donor materials in solar cells active layers. It can be said that this is an expected result because these substituents $\mathrm{N}\left(\mathrm{CH}_{3}\right)_{2}, \mathrm{NH}_{2}, \mathrm{OH}$, and $\mathrm{OCH}_{3}$ have a strong tendency to donate electrons to the main chain $(\sigma<0)$. Likewise, the sector with $\lambda_{\text {hole }} / \lambda_{\text {electron }}<1$ is dominated by substituents that tend to withdraw electrons from the main chain $(\sigma>0)$, although we can see some substituents with a slight tendency to donate electrons $\left(\mathrm{CH}_{3}, \mathrm{C}_{2} \mathrm{H}_{5}, \mathrm{C}_{3} \mathrm{H}_{7}, \mathrm{C}_{4} \mathrm{H}_{9}\right.$, and $\left.\mathrm{CH}=\mathrm{CH}_{2}\right)$. Nevertheless, the lowest values for $\lambda_{\text {hole }} / \lambda_{\text {electron }}$ seem to be localized close to $\sigma=0$. Our interpretation is that the best results are obtained for substituents that do not interfere in the main chain electron system, i.e., have a minimum charge exchange with the main chain. And perhaps other factors may be responsible for the improvement in $\lambda_{\text {hole }} / \lambda_{\text {electron }}$, since again we see bulky groups with

Table 1

Hammet constants for most of the substituents in this study.

\begin{tabular}{|c|c|c|c|}
\hline Substituent & $\sigma_{1}$ & $\sigma_{\mathrm{R}}$ & $\sigma=\sigma_{\mathrm{I}}+\sigma_{\mathrm{R}}$ \\
\hline H (P3HT without substituents) & 0 & 0 & 0 \\
\hline $\mathrm{Cl}$ & 0.47 & -0.25 & 0.22 \\
\hline $\mathrm{Br}$ & 0.47 & -0.25 & 0.22 \\
\hline $\mathrm{F}$ & 0.54 & -0.48 & 0.06 \\
\hline $\mathrm{OH}$ & 0.24 & -0.62 & -0.38 \\
\hline $\mathrm{CN}$ & 0.47 & 0.08 & 0.55 \\
\hline $\mathrm{NH}_{2}$ & 0.17 & -0.80 & -0.63 \\
\hline $\mathrm{SCH}_{3}$ & 0.30 & - & 0.30 \\
\hline $\mathrm{CF}_{3}$ & 0.40 & 0.11 & 0.51 \\
\hline $\mathrm{CH}_{3}$ & -0.01 & -0.16 & -0.17 \\
\hline $\mathrm{C}_{2} \mathrm{H}_{5}$ & -0.01 & -0.14 & -0.15 \\
\hline $\mathrm{C}_{3} \mathrm{H}_{7}$ & - & - & $-0.13^{\mathrm{a}}$ \\
\hline $\mathrm{C}_{4} \mathrm{H}_{9}$ & - & - & $-0.13^{a}$ \\
\hline $\mathrm{N}\left(\mathrm{CH}_{3}\right)_{2}$ & 0.13 & -0.88 & -0.75 \\
\hline $\mathrm{OCH}_{3}$ & 0.30 & -0.58 & -0.28 \\
\hline $\mathrm{CO}_{2} \mathrm{H}$ & 0.30 & 0.11 & 0.41 \\
\hline $\mathrm{CH}=\mathrm{CH}_{2}$ & 0.11 & -0.15 & -0.04 \\
\hline $\mathrm{Ph}$ & 0.12 & -0.11 & 0.01 \\
\hline
\end{tabular}

${ }^{a}$ Estimated values (see text).

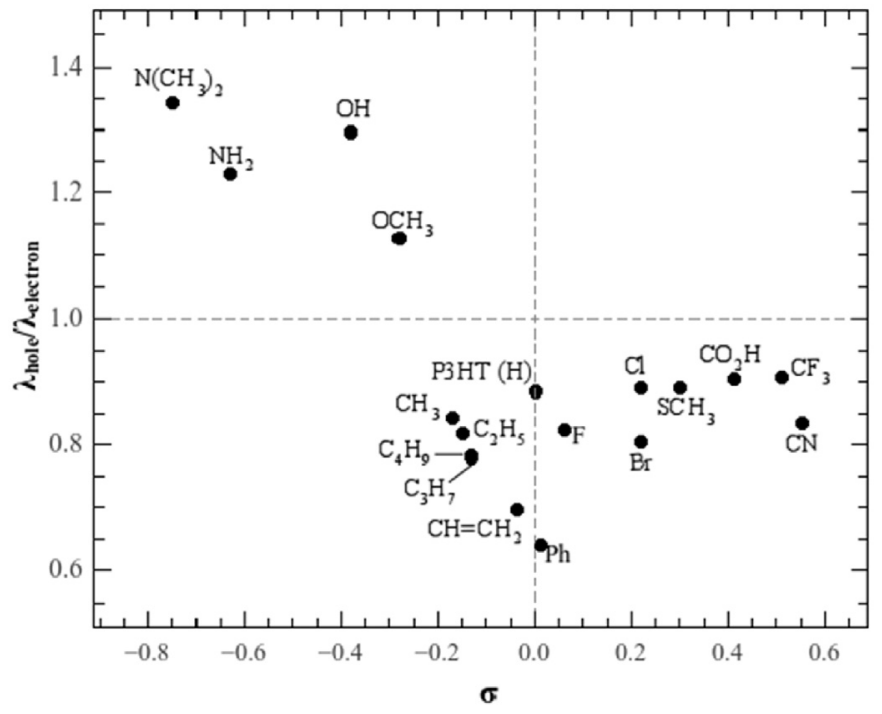

Fig. 5. The ratio between reorganization energy for holes and electrons transfer versus the Hammet constant $\sigma$ (for donor polymers $\lambda_{\text {hole }} / \lambda_{\text {electron }}$ should be lower than unity).

the best results.

Our results seem to indicate that $\lambda_{\text {hole }} / \lambda_{\text {electron }}$ is directly proportional to the absolute value of $\sigma$ and inversely proportional to the substituent's volume. Fig. 6 shows that, in fact, if there is no clear rule, at least there is a rough correlation between $\lambda_{\text {hole }} / \lambda_{\text {electron }}$ and $|\sigma| /$ volume, from which we can get some clues that lead us to propose a filtering scheme to choose the type of substituent that can be used to improve hole mobility in conjugated polymers. Firstly, we have to look at the most important aspect that is how the substituents modify the electronic density of the polymer, choosing those that do not interfere significantly in the amount of electrons of the polymer main chain. It is possible to note that those who are strong electron donors can not be employed because they always tend to favour the transport of electrons; the other cases indicate that the transport of holes will be improved over that of electrons (see Fig. 5). Secondly, to further optimize the desired results, we can

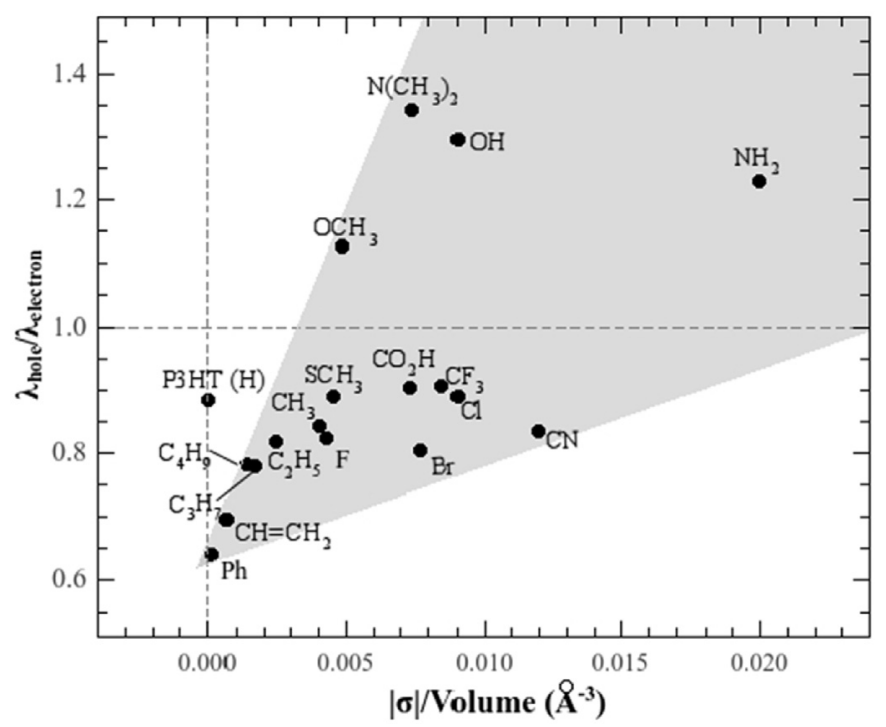

Fig. 6. The ratio between reorganization energy for holes and electron transfer versus the ratio between the absolute value of Hammet constant $\sigma$ and substituent's volume (for donor polymers $\lambda_{\text {hole }} / \lambda_{\text {electron }}$ should be lower than unity). 
employ substituents with large volumes that tend to decrease the reorganization energy of the polymer, rigidifying the main chain.

Based on the clues above, lets see what should be the best choices for set of compounds studied in this paper, prior to the calculations. The substituents with $|\sigma|<0.2$ are $\mathrm{Ph}, \mathrm{F}, \mathrm{CH}=\mathrm{CH}_{2}$, $\mathrm{C}_{3} \mathrm{H}_{7}, \mathrm{C}_{4} \mathrm{H}_{9}, \mathrm{C}_{2} \mathrm{H}_{5}$, and $\mathrm{CH}_{3}$; from this subset, $\mathrm{C}_{4} \mathrm{H}_{9}$ has the higher volume, followed by $\mathrm{Ph}$ and $\mathrm{C}_{3} \mathrm{H}_{7}$. Indeed, after the our calculations, this subset present very interesting values for $\lambda_{\text {hole }}$ and $\lambda_{\text {hole }} / \lambda_{\text {electron }}$ which are: $0.311 \mathrm{eV}$ and $0.780,0.279 \mathrm{eV}$ and 0.642 , and $0.307 \mathrm{eV}$ and 0.780 , respectively. Only for comparison, the lowest values are $0.264 \mathrm{eV}$ (TPA) for $\lambda_{\text {hole }}$ and 0.643 (Ph) for $\lambda_{\text {hole }} / \lambda_{\text {electron}}$. We believe that these results confirm the scheme proposed.

On the other hand, if one already has the results of the calculations, in order to decide which substituent have an expectation of being a better transporter of holes, instead of Fig. 6 , the first and most important parameter to be observed is the value of $\lambda_{\text {hole }}$, which should be the lowest possible; the second parameter, is the ratio $\lambda_{\text {hole }} / \lambda_{\text {electron }}$ which should be lower than 1 . From the substituents for that we have the Hammett constants and $\lambda_{\text {hole }} / \lambda_{\text {elec- }}$ tron $<1$, the five best are $\mathrm{CH}=\mathrm{CH}_{2}, \mathrm{Ph}, \mathrm{C}_{3} \mathrm{H}_{7}, \mathrm{C}_{4} \mathrm{H}_{9}$, and $\mathrm{C}_{2} \mathrm{H}_{5}$ ( $\lambda_{\text {hole }}=0.291,0.297,0.307,0.311$, and 0.325 , respectively).

According to our previous study about P3HT derivatives in solid state, when inserting substituents smaller than the hexyl side chain of the P3HT in the empty beta-position of thiophenic rings, we did not observe huge distortions in the polymer backbone compared to pure P3HT [16]. As in this work the substituents employed are smaller than the original side chains of P3HT, it is expected that the P3HT derivatives studied here do not present problems regarding less crystallinity and poorer packing in the solid state.

In the literature, some attempts are found to correlate the reorganization energy of the polymer with certain properties such as bond length alternation and inter-ring dihedral angles, among others $[19,74]$. The main conclusion is that approximately half of the changes in reorganization energy can be attributed to geometrical parameters [19]. This result is in agreement with our findings, since we observe evidence of correlation only when electronic and geometric properties are combined.

Fig. 6 brings us the best picture we could find to understand the problem of modeling new donor compounds that could improve the transport properties, for which $\lambda_{\text {hole }}$ should be smaller than

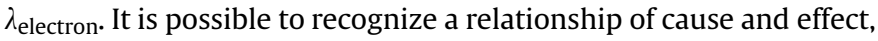
in which the charge exchange character and the volume of the substituents seem to play important roles. However, the set of the best substituents remain practically the same as in Table S1 (see the Electronic Supplementary Material) in which the results for $\lambda_{\text {hole }}$ are shown in ascending order. The set of substituents with the seven smaller $\lambda_{\text {hole }}$ are $\mathrm{CH}=\mathrm{CH}_{2}, \mathrm{Ph}, \mathrm{C}_{3} \mathrm{H}_{7}, \mathrm{C}_{4} \mathrm{H}_{9}, \mathrm{C}_{2} \mathrm{H}_{5}, \mathrm{Cl}$, F, while in Fig. 6 one can say that the seven best substituents are $\mathrm{Ph}, \mathrm{CH}=\mathrm{CH}_{2}$, $\mathrm{C}_{4} \mathrm{H}_{9}, \mathrm{C}_{3} \mathrm{H}_{7}, \mathrm{C}_{2} \mathrm{H}_{5}, \mathrm{~F}, \mathrm{CH}_{3}$. In other words, the calculation of $\lambda_{\text {hole }}$ seems to be enough to indicate good candidates, but what are the directions to look for new candidates? One should consider groups with low charge exchange and large volumes, but not so large in comparison of the alkyl side groups in order to avoid packing problems.

When considering the influence of chemical substitutions on both transport and electronic properties, we can draw some conclusions based in this and our previous works about the electronic structure of P3HT derivatives [15,16]. From the electronic point of view, the best substituents are the groups which tend to withdraw electrons from the polymeric main chain: $\mathrm{CN}, \mathrm{Cl}, \mathrm{F}, \mathrm{Br}, \mathrm{COOH}$, and $\mathrm{CF}_{3}$. Overall, this is the set of recommended substituents: (i) if they are not the ones with the best transport properties, at least they provide enhanced hole transport over P3HT, favouring a higher mobility of holes than of electrons, and simultaneously (ii) stabilize the highest occupied molecular orbital (HOMO) that in general improves the open circuit voltage [16]. P3HT-Ph, one of the derivatives with the most enhanced hole transport, has practically the same energies for the frontier electronic levels as P3HT [15]; i.e., there are no improvements coming from the electronic properties. Our main conclusion from our works with P3HT derivatives is that if the electronic properties are enhanced, then the transport properties will be improved.

For blends with PCBM, considering our previous and present results, the fluorinated derivative is the one with the best set of improvements over the P3HT, since the frontier electronic levels are closer to the ideal values and the transport of holes tends to be better [16]; these results are consistent with what is observed experimentally [30,34-36]. This indicates that our methodology is valid for testing new P3HT derivatives and probably other conjugated polymers also. Additionally, our results predict that there are substituents that can be more interesting than fluorine, if one considers another acceptor compounds, for which the frontiers electronic orbitals present a better match than for PCBM.

\section{Conclusions}

The theoretical approach adopted to estimate the reorganization energy, a property that directly influences the transport properties of conjugated polymers, is supported by the results for $\mathrm{P} 3 \mathrm{HT}$, for which we obtained $\lambda_{\text {hole }}<\lambda_{\text {electron }}$ in agreement with experiments $[25,26]$, and the prediction that the fluorinated derivative tends to improve hole mobility, as observed experimentally for other compounds [30,34-36]. Our results also show the same trends as a similar theoretical study with anthracene, when the same chemical substitutions are considered [74].

Overall, chemical substitutions improve charge mobility of P3HT, but some types of substituents can favour the transport of electrons instead of holes. Applying a joint analysis employing Hammet constants and the volume of the substituents, the results obtained suggest that to achieve greater hole mobility we can choose large substituents, since that they are not larger than the hexyl side chains of the P3HT, that do not promote charge exchange with the polymer backbone. For example, $\mathrm{C}_{2} \mathrm{H}_{5}$ presents better results than $\mathrm{CH}_{3}$, since it is larger and promotes a smaller charge exchange.

Although our calculations were done only for P3HT derivatives, based on the agreement between our results and those for anthracene derivatives and several fluorinated conjugated materials, we believe that the same trends may be observed also for other systems.

\section{Acknowledgments}

We would like to thank the Brazilian agency FAPESP (proc. 2012/ 21983-0 and 2014/20410-1) for financial support. This research was also supported by resources supplied by the Center for Scientific Computing (NCC/GridUNESP) of the São Paulo State University (UNESP).

\section{Appendix A. Supplementary data}

Supplementary data related to this article can be found at http:// dx.doi.org/10.1016/j.polymer.2016.07.003.

\section{References}

[1] Z. He, B. Xiao, F. Liu, H. Wu, Y. Yang, S. Xiao, C. Wang, T.P. Russell, Y. Cao, Nat Phot. 9 (2015) 174-179.

[2] Z. Li, H.C. Wong, Z. Huang, H. Zhong, C.H. Tan, W.C. Tsoi, J.S. Kim, J.R. Durrant J.T.P. Cabral, Nat. Commun. 4 (2013), 2227(1-7).

[3] E. Bundgaard, F.C. Krebs, Sol. Energy Mater. Sol. Cells 91 (2007) 954-985. 
[4] S. Günes, H. Neugebauer, N.S. Sariciftci, Chem. Rev. 107 (2007) 1324-1338.

[5] R.J. Gaudiana, J. Polym. Sci. Part B Polym. Phys. 50 (2012) 1014-1017.

[6] P.W.M. Blom, V.D. Mihailetchi, L.J.A. Koster, D.E. Markov, Adv. Mat. 19 (2007) $1551-1566$.

[7] G. Li, R. Shu, Y. Yang, Nat. Phot. 6 (2012) 153-161.

[8] S. Lee, J.-S. Yeo, Y. Ji, C. Cho, D.-Y. Kim, S.-I. Na, B.H. Lee, T. Lee, Nanotechnology 23 (2012), 344013(1-6).

[9] T. Ameri, J. Min, N. Li, F. Machui, D. Baran, M. Forster, K.J. Schottler, D. Dolfen, U. Scherf, C.J. Brabec, Adv. Energy Mater. 2 (2012) 1198-1202.

[10] M.C. Scharber, Adv. Mater. 28 (2016) 1994-2001, http://dx.doi.org/10.1002/ adma.201504914.

[11] S.H. Oh, S.J. Heo, J.S. Yang, H.J. Kim, ACS Appl. Mater. Interfaces 5 (2013) $11530-11534$.

[12] E.F. Oliveira, F.C. Lavarda, J. Polym. Sci. Part B Polym. Phys. 51 (2013) $1350-1354$.

[13] D. Chi, S. Qu, Z. Wang, J. Wang, J. Mater. Chem. C 2 (2014) 4383-4387.

[14] D.M. González, V. Körstgens, Y. Yao, L. Song, G. Santoro, S.V. Roth, P. MüllerBuschbaum, Adv. Energy Mater. 5 (2015), http://dx.doi.org/10.1002/ aenm.201401770.

[15] E.F. Oliveira, A. Camilo Jr., L.C. da Silva-Filho, F.C. Lavarda, J. Polym. Sci. Part B Polym. Phys. 51 (2013) 842-846.

[16] E.F. Oliveira, F.C. Lavarda, Mater. Chem. Phys. 148 (2014) 923-932.

[17] B. Ebenhoch, S.A.J. Thomson, K. Genevicius, G. Juska, I.D.W. Samuel, Org. Electron. 22 (2015) 62-68.

[18] J.A. Barlett, D. Lam, T.M. Burke, S.M. Sweetnam, M.D. McGehee, Adv. Energy Mater. 5 (2015), http://dx.doi.org/10.1002/aenm.201500577.

[19] G.R. Hutchison, M.A. Ratner, T.J. Marks, J. Am. Chem. Soc. 127 (2005) 2339-2350.

[20] H. Geng, Y. Niu, Q. Peng, Z. Shuai, V. Coropceanu, J.-L. Brédas, J. Chem. Phys. 135 (2011), 104703(1-7).

[21] A. Amini, A.J. Harriman, Photochem. Photobiol. C Photochem. Rev. 4 (2003) $155-177$.

[22] Y.-K. Lan, C.-I. Huang, J. Phys. Chem. B 112 (2008) 14857-14862.

[23] G. Garcia-Belmonte, A. Munar, E.M. Barea, J. Bisquert, I. Ugarte, R. Pacios, Org. Electron. 9 (2008) 847-851.

[24] V.D. Mihailechi, H. Xie, B. de Boer, L.J.A. Koster, P.W.M. Blom, Adv. Funct Mater. 16 (2006) 699-708.

[25] I. Kang, H.-J. Yun, D.S. Chung, S.-K. Kwon, Y.-H. Kim, J. Am. Chem. Soc. 135 (2013) 14896-14899.

[26] G.-J.A.H. Wetzelaer, M. Kuik, Y. Olivier, V. Lemaur, J. Cornil, S. Fabiano, M.A. Loi, P.W.M. Blom, Phys. Rev. B 86 (2012), 165203(1-9).

[27] S. Zade, N. Zamoshchik, M. Bendikov, Acc. Chem. Res. 44 (2010) 14-24.

[28] H.-J. Wang, C.-P. Chen, R.-J. Jeng, Materials 7 (2014) 2411-2439.

[29] K. Yoshino, Y. Manda, K. Sawada, S. Morita, H. Takahashi, R.-I. Sugimoto, M. Onoda, J. Phys. Soc. Jpn. 58 (1989) 1320-1324.

[30] Z. Fei, P. Boufflet, S. Wood, J. Wade, J. Moriarty, E. Gann, E.L. Ratcliff, C.R. McNeill, H. Sirringhaus, J.-S. Kim, M. Heeney, J. Am. Chem. Soc. 137 (2015) 6866-6879.

[31] Y. Li, G. Vamvounis, S. Holdcroft, Macromolecules 34 (2001) 141-143.

[32] Y. Li, G. Vamvounis, S. Holdcroft, Macromolecules 35 (2001) 6900-6906.

[33] M. Qiu, R.G. Brandt, Y. Niu, X. Bao, D. Yu, N. Wang, L. Han, L. Yu, S. Xia, R. Yang, J. Phys. Chem. C 119 (2015) 8501-8511.

[34] A.C. Stuart, J.R. Tumbleston, H. Zhou, W. Li, S. Liu, H. Ade, W. You, J. Am. Chem. Soc. 135 (2013) 1806-1815.

[35] T. Umeyama, Y. Watanabe, E. Douvogianni, H. Imahori, J. Phys. Chem. C 117 (2013) 21148-21157.

[36] Y. Lu, Z. Xiao, Y. Yuan, H. Wu, Z. An, Y. Hou, C. Gao, J. Huang, J. Mater. Chem. C 1 (2013) 630-637.

[37] A. Melianas, F. Etzold, T.J. Savenije, F. Laquai, O. Inganäs, M. Kemerink, Nat. Commun. 6 (2015), http://dx.doi.org/10.1038/ncomms9778.

[38] N.M. O'Boyle, C.M. Campbell, G.R. Hutchison, J. Phys. Chem. C 115 (2011) $16200-16210$.

[39] J. Kjelstrup-Hansen, J.E. Norton, D.A. da Silva Filho, J.-L. Brédas, H.-G. Rubahn, Org. Electron. 10 (2009) 1228-1234.

[40] H. Sanu, A.N. Panda, Phys. Chem. Chem. Phys. 16 (2014) 8563-8574.

[41] Y. Li, Y. Feng, M. Sun, Sci. Rep. 5 (2015), http://dx.doi.org/10.1038/srep13970.
[42] G. García, M. Moral, A. Garzón, J.M. Granadino-Roldán, A. Navarro, M. Fernández-Gómez, Org. Electron 13 (2012) 3244-3253.

[43] C. Poelking, K. Daoulas, A. Troisi, D. Andrienko, Adv. Polym. Sci. 265 (2014) 139-180.

[44] R.G. Parr, W. Yang, in: Density-functional Theory of Atoms and Molecules, vol. 1, Oxford University Press, New York, 1989, pp. 47-66 (Chapter 3).

[45] S. Yang, P. Olishevski, M. Kertesz, Synth. Met. 141 (2004) 171-177.

[46] E.F. Oliveira, F.C. Lavarda, Mat. Res. 17 (2014) 1369-1374.

[47] E.F. Oliveira, F.C. Lavarda, Polym. Eng. Sci. 56 (2016) 479-487.

[48] A. Batagin-Neto, E.F. Oliveira, C.F.O. Graeff, F.C. Lavarda, Mol. Simul. 39 (2013) 309-321.

[49] P. Sista, C.K. Luscombe, Adv. Polym. Sci. 265 (2014) 1-38.

[50] Y. Li, in: Organic Optoelectronic Materials, vol. 1, Springer International Publishing, Cham, 2015, pp. 202-210 (Chapter 5).

[51] W.D. Cornell, P. Cieplak, C.I. Bayly, I.R. Gould, K.M. Merz, D.M. Ferguson, D.C. Spellmeyer, T. Fox, J.W. Caldwell, P.A. Kollman, J. Am. Chem. Soc. 117 (1995) 5179-5197.

[52] A.R. Allouche, J. Comput. Chem. 32 (2011) 174-182.

[53] J.J.P. Stewart, J. Mol. Model. 13 (2007) 1173-1213.

[54] J.J.P. Stewart, MOPAC: Molecular Orbital Package, Stewart Computational Chemistry, http://www.openmopac.net/MOPAC2012.html (accessed 03.11.15).

[55] R.C. Hiorns, P. Iratçabal, D. Bégué, A. Khoukh, R. De Bettignies, J. Leroy, M. Firon, C. Sentein, H. Martinez, H. Preud'homme, C. Dagron-Lartigau, J. Polym. Sci. Part A Polym. Chem. 47 (2009) 2304-2317.

[56] I.Y. Kanal, S.G. Owens, J.S. Bechetel, G.R. Hutchison, J. Phys. Chem. Lett. 4 (2013) 1613-1623.

[57] F. Jensen, in: Introduction to Computational Chemistry, vol. 2, John Wiley \& Sons, Nova Jersey, 2007, pp. 99-100 (Chapter 3).

[58] M.W. Schmidt, K.K. Baldridge, J.A. Boatz, S.T. Elbert, M.S. Gordon, J.H. Jensen, S. Koseki, N. Matsunaga, K.A. Nguyen, S.J. Su, T.L. Windus, M. Dupuis, J.A. Montgomery, J. Comput. Chem. 14 (1993) 1347.

[59] T.M. McCormik, C.R. Bridges, E.I. Carrera, P.M. DiCarmine, G.L. Gibson, J. Hollinger, L.M. Kozycz, D.S. Seferos, Macromolecules 46 (2013) 3879-3886.

[60] W.J. Hehre, in: A Guide to Molecular Mechanics and Quantum Chemical Calculations, vol. 1, Wavefunction, Inc., Irvine, 2003, pp. 40-46 (Chapter 2).

[61] E.F. Oliveira, J.C. Roldao, B. Milián-Medina, F.C. Lavarda, J. Gierschner, Chem. Phys. Lett. 645 (2016) 169-173.

[62] S.F. Sousa, P.A. Fernandes, M.J.G. Ramos, J. Phys. Chem. A 111 (2007) 10439-10452.

[63] Y.S. Cho, R.R. Franklin, Trans. Electr. Electron. Mater. 13 (2012) 237-240.

[64] A. Klant, G. Schüürmann, J. Chem. Soc. Perkin. Trans. 2 (1993) 799-805.

[65] H. Nakanishi, Y. Aso, N. Sumi, T. Otsubo, J. Org. Chem. 63 (1998) 8632-8633.

[66] S. Kishino, Y. Ueno, K. Ochiai, M. Rikukawa, K. Sanui, T. Kobayashi, H. Kunugita, K. Ema, Phys. Rev. B 58 (1998). R13430(R).

[67] T. Izumi, S. Kobashi, K. Takimiya, Y. Aso, T. Otsubo, J. Am. Chem. Soc. 125 (2003) 5286-5287.

[68] Z. Shuai, L. Wang, C. Song, Theory of Charge Transport in Carbon Electronic Materials, vol. 1, Springer, Berlin, 2012, pp. 7-41 (Chapter 2).

[69] D. Alberga, A. Perrier, I. Ciofini, G.F. Mangiatordi, G. Lattanzi, C. Adamo, Phys. Chem. Chem. Phys. 17 (2015) 18742-18750.

[70] I.F. Perepichka, D.F. Perepichka, Handbook of Thiophene-based Materials: Applications in Organic Electronics and Photonics, vol. 2, Wiley, 2009, pp. $1-155$ (Chapter 1).

[71] A.A.Y. Guilbert, M. Zbiri, M.V.C. Jenart, C.B. Nielsen, J. Nelson, J. Phys. Chem. Lett. 7 (2016) 2252-2257.

[72] N.R. Tummala, C. Risko, C. Bruner, R.H. Dauskardt, J.-L. Brédas, J. Polym. Sci. Part B Polym. Chem. 13 (2015) 934-942.

[73] S. Obata, Y. Shimoi, Phys. Chem. Chem. Phys. 15 (2013) 9265-9270.

[74] Y.H. Park, Y.-H. Kim, S.K. Kwon, I.S. Koo, K. Yang, Bull. Korean Chem. Soc. 31 (2010) 1649-1655.

[75] F. Carey, R.J. Sundberg, Advanced Organic Chemistry Part A: Structure and Mechanisms, vol. 5, Springer, New York, 2007, pp. 123-177 (Chapter 3).

[76] J.E. McMurry, Organic Chemistry, vol. 7, Cenage Learning, Belmont, 2007, pp. 137-171 (Chapter 5). 